\title{
Hjemmemonitor gir trygghet
}

Med implantert hjertestarter og hjemmemonitor kan pasientene overvåkes hjemmefra og trenger færre kontroller i poliklinikk.

\section{Forfattere}

\section{Kristin J. Ramstad}

Spesialsykepleier i kardiologisk sykepleie

Hjerteavdelingen, Haukeland universitetssjukehus

\section{Svein Færestrand}

Hjertespesialist, seksjonsleder og professor

Hjerteavdelingen, Haukeland universitetssjukehus og Universitetet i Bergen

\section{Bjørg Anita Dalseid}

Sykepleier

Hjerteavdelingen, Haukeland universitetssjukehus

\section{Merete Drønen}

Spesialsykepleier i kardiologisk sykepleie og masterstudent

Fitjar kommune og Høgskolen i Bergen

\section{Tone Merete Norekvål}

Fag- og forskningssykepleier og professor

Haukeland universitetssjukehus, Universitetet i Bergen og Høgskolen på Vestlandet

\section{Nøkkelord}

Hjertesvikt Hjertestater Poliklinikk

Sykepleien 2017 105(8)(64-67)

DOI: https://doi.org/10.4220/Sykepleiens.2017.63162 
Stadig flere pasienter får operert inn hjertestarter, og sykehuspoliklinikkene må dermed følge opp et økende antall pasienter. Hjemmemonitorering av implanterbar hjertestarter ble først tatt i bruk i Norge i 2008. Siden den gang har stadig flere pasienter fått et slikt tilbud. De får fremdeles tilstrekkelig oppfølging, selv om de ikke møter like ofte til polikliniske timer.

Samtidig tar de større del i egen oppfølging. Pasientene må bruke hjemmemonitoren korrekt og selv legge til rette for å overføre data fra monitor til hjertepoliklinikkene.

Med teknologi i stadig utvikling kreves det mer av

både helsepersonell og pasienter. Behovet for

kunnskap og informasjon er stort. I 2016 fikk 959

pasienter i Norge operert inn hjertestarter (ICD Implantable Cardioverter Defibrillator), mot 891 i 2015 (1). Ifølge internasjonale retningslinjer skal pasientene følges opp jevnlig med kontroller hver tredje til sjette måned, med hyppigere kontroller når det nærmer seg tid for batteribytte (2). Kontrollene utføres ved sykehuspoliklinikker av hjertespesialister med spesialkompetanse innen ICD-behandling.

Et høyere antall pasienter med ICD som skal kontrolleres, har gitt et større press på poliklinikkene. Behov for øyeblikkelig hjelp kan også oppstå og utløse fremmøtekontroller i poliklinikken. Det kan være symptomgivende hjerterytmeforstyrrelse, innslag fra ICD, økende grad av hjertesvikt og i noen sjeldne tilfeller tekniske problemer med enheten som gjør at pasienten må undersøkes (3-4).

Hensikten med denne artikkelen er å belyse hvilke behov pasienter med ICD har som er knyttet til oppfølging med hjemmemonitor.

\section{Fjernkontroll av ICD}

Tilgjengelig teknologi for fjernkontroll med webbaserte nettverk har åpnet for hjemmekontroll av ICD. Haukeland universitetssjukehus var første sykehus i Norge til å ta i bruk slik teknologi i 2008, tett fulgt av Universitetssykehuset Nord-Norge. Siden den gang har stadig flere pasienter fått mulighet til slik hjemmemonitorering (4). Haukeland universitetssjukehus har i dag over 500 pasienter med hjemmemonitor fra fire ulike ICD-leverandører. 
Den første ICD-produsenten som kunne tilby sine ICD-bærere hjemmemonitorering, gjorde dette så tidlig som i 2001. De fleste hjemmemonitorene overfører automatisk data fra ICD når pasienten er i nærheten av monitoren. For hjemmemonitorering av eldre ICD-er må pasienten selv aktivere systemet ved å trykke på en knapp på monitoren for å overføre data fra ICD-en (3-5).

\section{BEGREPSFORKLARINGER}

Hjemmemonitorering: Webbasert poliklinisk oppfølging. ICD-enheten er utstyrt med en mikroantenne som overfører data til en ekstern overfører (hjemmemonitor). Data overføres så via GSM-nett til en sikker database som helsepersonell kan logge seg på via internett.

ICD: Implantert hjertestarter som overvåker hjerterytmen og kan gi elektrisk sjokk for å avbryte en livstruende rask arytmi. Den har også funksjon som en pacemaker som behandler langsom hjerterytme ved å gi elektrisk stimulering av hjertet.

Implantasjon: Foregår i lokalbedøvelse. ICD-enheten legges under huden fortrinnsvis nedenfor venstre kragebein.

Oppfølging: Kontroll i poliklinikk én måned etter implantasjon, deretter én gang i året. Kontroll hver tredje til sjette måned med hjemmemonitor.

Primærprofylaktisk indikasjon: Livstruende arytmi har ikke oppstått, men pasienten har økt risiko på bakgrunn av hjertesykdom. Pasienter med hjertesvikt eller pasienter som er genetisk disponert for alvorlig arytmi (for eksempel langt QT-syndrom, arytmogen høyre ventrikkelkardiomyopati [ARVC Arrhythmiogenic Right Ventricular Cardiomyopathy], hypertrofisk kardiomyopati [HOCM - Hypertrophic Obstructive Cardiomyopathy]) er aktuelle kandidater.

Sekundærprofylaktisk indikasjon: Pasienten har hatt livstruende arytmi: vedvarende rask ventrikkeltakykardi eller ventrikkelflimmer som ikke er utløst av forbigående tilstander eller tilstander som kan behandles.

Sykehusinnleggelse: Ved planlagt ukomplisert ICDimplantasjon varer sykehusoppholdet to til tre dager. 


\section{Å leve med ICD}

Noen pasienter har hatt alvorlig hjertehendelse som hjertestans, eller alvorlig symptomgivende rask hjerterytme før implantasjon (sekundærprofylaktisk indikasjon). Andre som har fått ICD, har vært uten slike symptomer, men har en hjertesykdom med høy risiko for å få slike alvorlige hendelser (primærprofylaktisk indikasjon).

Pasientene har ulik opplevelse av det å ha fått behov for ICD. For noen kan det å ha en ICD være en vedvarende påminning om deres alvorlige hjertesykdom (6). For å motvirke den angsten som kan være forbundet med det å ha ICD, er det viktig med praktisk informasjon om situasjoner som kan oppstå i dagliglivet, og om hvilke forholdsregler pasienten skal ta (7). Det er derfor essensielt at legene og sykepleierne tar seg tid til å informere om ICDbehandlingen og svare på spørsmål fra pasienten og pårørende.

\section{«Hensikten med hjemmemonitorering er å gi pasienten en tryggere og bedre behandling som også bedrer deres overlevelse.»}

Hensikten med hjemmemonitorering er å gi pasienten en tryggere og bedre behandling som også bedrer deres overlevelse. Pasientene er selv ansvarlige for å legge til rette for at overføring av data fra ICD via hjemmemonitoren kan gjennomføres. Derfor må de alltid veiledes detaljert og grundig i hvordan hjemmemonitor skal brukes. Pasientene må passe på å ha hjemmemonitoren koplet opp, og de må oppholde seg i nærheten av den ved tidspunktet for overføring. Enkelte pasienter tror at de ikke har behov for hjemmemonitoren. Årsaken kan være at de er engstelige for å ta i bruk ny teknologi og redde for å gjøre feil. 


\section{KASUISTIKK}

Olav, som er 65 år gammel, har gjennomgått et stort hjerteinfarkt med påfølgende hjertestans. Da risikoen for ny alvorlig hjertehendelse er til stede, får han operert inn en ICD sekundærprofylaktisk. Olav er enkemann med lang vei til både nærmeste nabo og sykehus. Da Olav reiste hjem fra sykehuset, fikk han med seg en hjemmemonitor. Han fikk opplæring av en sykepleier over telefon etter hjemkomsten.

Olav lever godt med sin ICD, og hver tredje til sjette måned gjennomføres planlagte kontroller via hjemmemonitoren. Etter hver innsending blir han kontaktet av en sykepleier fra poliklinikken.

Sykepleieren informerer om eventuelle hendelser som ICD-en har registrert, og om status på enhetens batterilevetid. Olav har også mulighet til selv å kontakte sykepleieren per telefon.

\section{Hjertestarter (ICD)}

En ICD opereres inn nedenfor venstre kragebein (figur 1). Enheten består av en pulsgenerator som inneholder batteri, mikroprosessor, elektriske kretser og kondensator. Den består også av sense-/paceelektrode i høyre hjertekammer (ventrikkel), ved behov også i høyre forkammer (atrium), samt defibrilleringscoiler plassert på elektroden i høyre hjertekammer.

Batterilevetiden er vanligvis fem til åtte år, avhengig av hvor mye ICD-enheten er aktiv i tillegg til hvor mye strøm som kreves for at elektroden skal gi impulser $(6,9)$. 
En ICD registrerer (senser) hvordan hjertet slår. Den vil oppdage for sakte hjerterytme (bradykardi), anfall av rask farlig hjerterytme (ventrikulær takykardi) samt hjertestans (ventrikkelflimmer/asystoli) (10). Ved senset bradykardi eller asystoli blir hjertet elektrisk stimulert (pacet), slik at man opprettholder hjerteaksjon $(6,10)$. Ved behov kan ICD-en umiddelbart behandle en alvorlig rytmeforstyrrelse.

Dersom ICD-enheten senser ventrikkeltakykardi, startes antitakykardipacing (ATP). Hjertet stimuleres da med en serie på seks til ti elektriske impulser som er litt raskere enn takykardien, og som derved kan gjenopprette normal hjerterytme. Denne behandlingen er helt smertefri for pasienten, og ofte oppdager pasienten ikke at vedkommende har hatt en alvorlig, livstruende rytmeforstyrrelse. Ved vedvarende rask ventrikkeltakykardi eller ved ventrikkelflimmer blir støt på 30-40 joule avgitt (defibrillering). Som regel er ett støt nok til å avbryte rytmeforstyrrelsen $(6,10)$. 
Ved alvorlige hendelser, slik som rask

ventrikkeltakykardi, vil som oftest pasienten besvime

før støt blir avgitt, men pasienter kan oppleve å få støt i våken tilstand. Det kan være en ubehagelig opplevelse å motta støt, men det varierer fra person til person. Pasientene beskriver det som «til å leve med» men også som «å bli slått med balltre». Dersom pasienten opplever å motta støt og føler seg kjekk i etterkant, kan lege eller kontrollsenter kontaktes samme eller påfølgende dag. Hvis derimot flere støt blir avgitt, eller hvis pasienten er uvel etter anfallet, skal man ringe etter ambulanse (9). Pasientene kan også oppleve å motta støt uten at det er hensiktsmessig. Det er to hovedgrunner til dette:

- supraventrikulær arytmi, oftest atrieflimmer, og

- feil med enheten som eksempelvis ledningsbrudd (9, 11).

Dersom pasienten har mistanke om at et sjokk er uhensiktsmessig, er det viktig å ta kontakt med lege straks, slik at ICD-en kan bli avlest og nødvendige tiltak iverksatt. Slike tiltak kan være å justere enhetens innstillinger, justere pasientens medisinering mot supraventrikulær takykardi eller bytte ledninger.

\section{Hjemmemonitorering}

Hjemmemonitorering har vist seg å være et godt alternativ til ICD-kontroll i poliklinikk (figur 2) (12). Monitoreringen foregår via et webbasert nettverk som tillater overføring av data over GSM-nettet (figur 3).

En ICD kommuniserer med hjemmemonitoren via en mikroantenne med rekkevidde på 0-3 meter for overføring (3-5). Overførte data lagres i sikre databaser. Autoriserte fagpersoner i poliklinikkene har tilgang til å lese av databasene med personlig passord (12). 
Hjemmemonitorering som ICD-leverandøren har utviklet, har litt ulike metoder for å lese av ICD-er, men alle benytter et lukket medisinsk og beskyttet system til å overføre data fra ICD-en til hjemmemonitoren. Det er så å si umulig at uvedkommende kan avlese data fra ICD-en eller hjemmemonitoren ved såkalt datahacking. Man kan heller ikke endre vitale innstillinger i ICD-en ved hjelp av en hjemmemonitor.

Figur 2: Trådløs hjemmemonitor

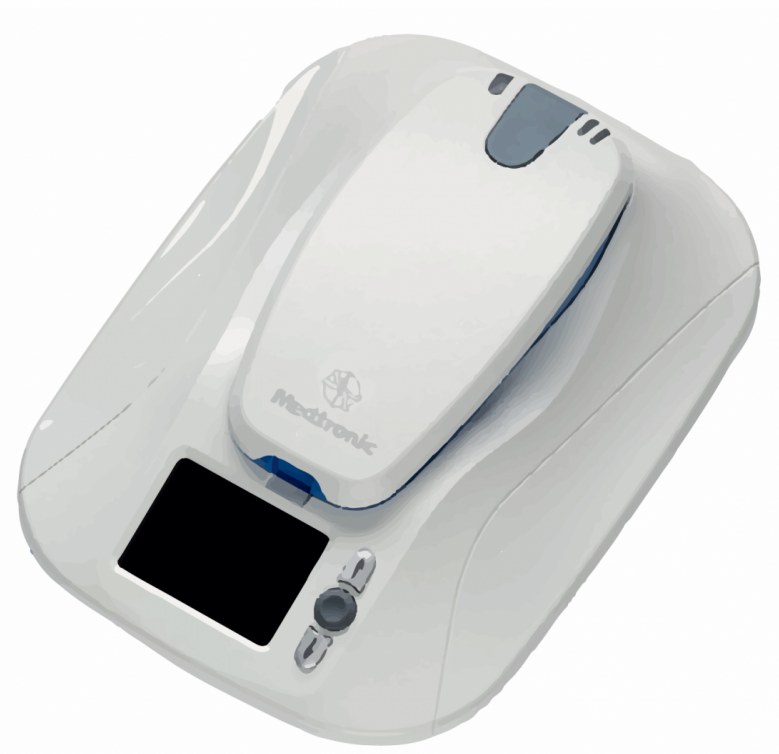

Hjemmemonitor med løst «hode» til å legge over ICD-enheten når data skal overføres (Foto: Medtronic).

Figur 3: Automatisk kontroll av ICD med innstilling av kontroll på sykehuset, overføring av data i hjemmet og sending

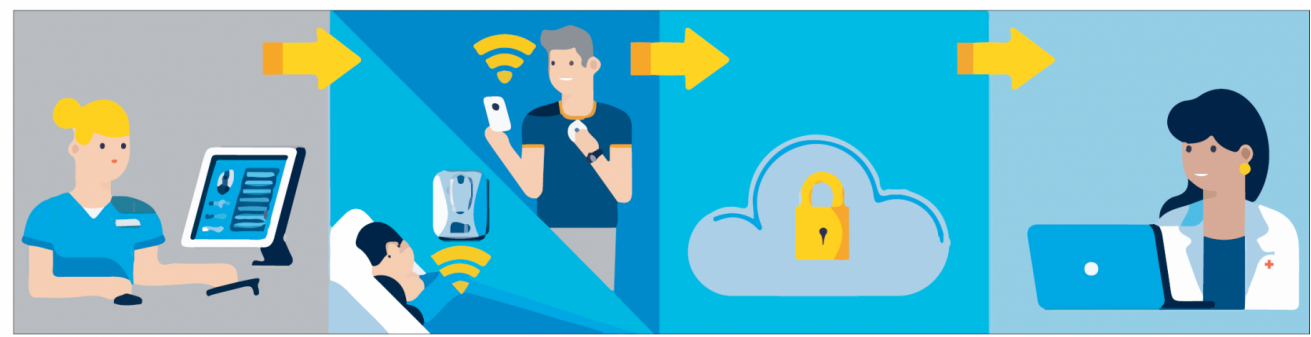

Sykepleieren stiller inn ønsket kontrolltidspunkt på nettsiden til det aktuelle hjemmemonitoreringssystemet. Hjemmemonitoren er plassert innenfor rekkevidde slik at ICD-enheten overfører data på innstilt tidspunkt. Data overføres til en sikker database som helsepersonellet har tilgang til i poliklinikk (Illustrasjon: Medtronic). 
Når hjemmemonitoren er koplet til internett, kan tidspunktet for kontrolloverføring fra ICD-en programmeres inn i pasientens ICD. Eksempelvis overfører et av systemene automatisk sendinger av data hver natt. Et annet sender data automatisk på tidspunktet som er stilt inn av personellet ved poliklinikken. Hvis det oppstår hendelser som overskrider de innprogrammerte alarmgrensene for ulike funksjoner i ICD-en, vil den automatisk overføre hendelsene når pasienten kommer nær hjemmemonitoren.

Med unntak av én ICD-leverandør har alle innopererte ICD-enheter alarm, enten som lydsignal eller vibrasjon eller begge deler, som pasienten kan høre eller føle når alarmgrenser overskrides. Disse alarmene gjentas frem til de programmerte tidspunktene slås av ved kontroll av ICD-en i poliklinikken på sykehuset. Da de fleste systemene nå er koplet til GSM-nettet, gir det mulighet til monitorering også borte fra hjemmet $(3-5,13)$.

\section{三 «De nyeste ICD-modellene selvtester de samme målingene som gjøres ved poliklinisk kontroll.»}

Pasientene møter fremdeles til polikliniske kontroller, men ikke like hyppig, da deler av kontrollene gjøres hjemmefra (2). Hvis det oppstår en hendelse, eller det er mistanke om en hendelse, kan informasjon sendes fra ICD-enheten. De nyeste ICD-modellene selvtester de samme målingene som gjøres ved poliklinisk kontroll. Man får også oversikt over eventuelle hjerterytmeforstyrrelser samt pasientens hjerterytme ved kontrolltidspunktet (4). 
For at hjemmemonitorering skal være effektivt, krever den oppmerksomhet både fra helsepersonell og pasient samt god opplæring av pasientene. Pasienten må sette opp monitoren slik at den er klar til bruk, ta med monitoren hvis vedkommende er borte over tid fra hjemmet, og passe på at monitoren har strøm. Disse momentene er avgjørende for at ICD-en skal kunne sende data (13).

\section{Brukermedvirkning}

Det blir stadig viktigere at pasienten skal medvirke i å følge opp egen helse og behandling. Brukermedvirkning er avgjørende i et helsefremmende perspektiv (14). Begrepet benyttes om ulike metoder som bidrar til at helsepersonell vektlegger pasientenes erfaringer, og det beskriver relasjonen mellom behandleren og pasienten. Den som mottar helsehjelp, involveres til å delta aktivt i behandlingen, og pasientens perspektiv preger i større grad utformingen av hjelpen som ytes $(15,16)$.

Pasientrettighetsloven §3-1 forankrer retten til medvirkning og bygger på prinsippet om selvbestemmelse (17). Samtidig vil det variere hvor mye pasienten deltar og hvilken innflytelse pasienten har, men målet er at pasienten medvirker optimalt sett fra sitt ståsted. Det er sentralt at lege og sykepleier ser viktigheten av brukermedvirkning og aktivt legger til rette for og inviterer til det (16).

Sykepleiere spiller en viktig rolle for pasientenes forståelse av og tilpasning til sin nye livssituasjon, som ICD og hjemmemonitorering innebærer (6). Det viktig at helsepersonellet formidler tro på pasientens mestringsevne for å bidra til at pasienten håndterer egen helse på en god måte. (14). Ved at Olav vet når og hvordan hjemmemonitoren skal brukes hvis han mistenker at det har oppstått en hendelse, og selv kontakter poliklinikk, er han aktiv i sin egen oppfølging (se kasuistikk). 


\section{Bedret livskvalitet}

Fra et pasientperspektiv vil nytten av å få implantert en ICD være å få bedret livskvaliteten siden alvorlige hjerterytmeforstyrrelser behandles øyeblikkelig og ofte smertefritt (ATP), og tidlig død kan forhindres. Noen pasienter har allerede opplevd alvorlige hjerterytmeforstyrrelser, mens andre har fått ICD fordi de har en hjertesykdom som gir høy risiko for alvorlige og ofte dødelige rytmeforstyrrelser. Den tryggheten en implantert ICD faktisk gir, må pasienten selv bli fortrolig med følelsesmessig, men grunnlaget må legges av legen og sykepleieren som behandler vedkommende (18).

Det er viktig å se hver pasient som enkeltindivider og kartlegge hva pasienten vet, og hvilket informasjonsbehov som foreligger. Begrepet «empowerment» beskriver en prosess som vektlegger omfordeling av innflytelse fra fagfolk til bruker. Med dette menes pasientens rett til å medvirke, få informasjon og bli hørt (19).

\section{三 «Etter en alvorlig hendelse kan en ICD gi trygghet.»}

Etter en alvorlig hendelse kan en ICD gi trygghet. Men for en pasient som har fått implantert ICD på grunn av fare for arytmi, kan det også være traumatisk å oppdage at faren for plutselig død er så stor at det er behov for hjertestarter (9). For Olav, som har overlevd hjertestans, kan en ICD bidra til trygghet. Når man ikke har pårørende rundt seg og lang vei til nærmeste sykehus, kan det gi større trygghet å ha mulighet til å få lest av ICD-en sin hjemmefra og ha kontakt med lege og sykepleier som veileder og støtter.

\section{Pasientveiledning}


For at pasientene skal kunne nyttiggjøre seg den tryggheten en ICD gir, er det viktig at sykepleiere veileder pasientene i hvordan de skal forholde seg til det å leve med ICD (18). Veiledning kan defineres på flere måter, blant annet som å legge til rette for læring og utvikling eller forandring, slik at den fremmer empowerment (19).

Når sykepleiere veileder pasienter, er de gitt en ekspertrolle - en rolle pasientene ofte etterspør. Pasientene ønsker gjerne å bli fortalt hva som er best for dem, og hva de skal gjøre. Det kan da bli en utfordring for sykepleiere å legge til rette for brukermedvirkning (19). Hvis sykepleiere som innehar denne ekspertrollen, har for dårlig forståelse av kunnskapsnivåene som kreves i behandlingen av pasienter med ICD, kan det føre til at pasientene ikke blir godt nok ivaretatt (7).

Sykepleiere kan bruke gode samtaleferdigheter som et middel til å forstå pasientene og yte bedre omsorg (20). Sykepleiere må være i stand til å møte pasientene med tilstrekkelig kunnskap og støttende kommunikasjon for å hjelpe dem med å godta å leve med sin ICD. Dette er spesielt viktig for de pasientene som har angst for å få elektrisk sjokk fra ICD-en (21). Når Olav mottar telefon etter sending via hjemmemonitoren, er det viktig at han blir møtt av en kompetent sykepleier som gir en oppdatering om hvordan ICD-en fungerer. Samtidig skal det være rom for at Olav kan stille spørsmål og få den nødvendige veiledningen han trenger.

\section{Fordeler og ulemper}


Automatisk overføring via hjemmemonitorering gir en kontinuerlig oppfølging av pasienter i stor skala og mye raskere diagnostikk av medisinske og tekniske hendelser hos ICD-pasientene. (22). Med hjemmemonitorering sparer pasientene og ofte pårørende som må følge, tid da resultatet fra hjemmemonitoreringen ofte viser at pasienten ikke trenger å reise til nærmeste poliklinikk. Olav sparer dermed en lang og kostbar reise $(11,23)$.

\section{三 «Over tid vil de fleste pasientene leve godt med sin ICD og oppnå en tilfredsstillende livskvalitet.»}

Over tid vil de fleste pasientene leve godt med sin ICD og oppnå en tilfredsstillende livskvalitet (21). Angsten for å motta elektrisk sjokk fra ICD, smerten ved avgitte sjokk og hyppigheten av sjokk kan ha store psykososiale konsekvenser og gi redusert livskvalitet. Andre utfordringer som opptar pasienten, er bekymring rundt sykdommen som førte til at ICD ble implantert, den kontinuerlige overvåkningen av ICDen og mestringen av å vende tilbake til et normalt liv $(18,21,24)$.

Støttende oppfølging fra lege og sykepleier kan virke positivt inn på pasienter som har angst for det å leve med ICD, samt gjøre pasienten tryggere på at ICD-en virker når den skal. Pasientene kan få høyere stressnivå og mer angst hvis oppfølgingen fra behandlende helsepersonell fremstår som likegyldig eller kritisk, og dermed ikke oppleves som støttende $(18,21)$. 
Når helsepersonell følger opp via hjemmemonitor, mister de muligheten til å kommunisere med pasienten ansikt til ansikt. Selv om hjemmemonitorering er besparende for sykehusene, kan den ikke erstatte direkte kontakt, som er viktig for mange pasienter ( 3 , 25). For at pasientene skal oppleve trygghet med hjemmemonitorering, er det viktig å ivareta forholdet til pasientene gjennom telefonkontakt, både ved overføring og ved manglende overføring $(22,25)$.

Pasientene med ICD-hjemmemonitor følges opp ved fremmøtekontroller hos hjertespesialist med kompetanse i ICD-behandling samt ved regelmessige besøk hos fastlege. Ofte kontrolleres disse pasientene også på sykehusets hjertesviktpoliklinikk for å optimalisere den medisinske behandlingen (26). Hensikten er å gi pasientene en best mulig medisinsk kontroll og behandling for sykdommen som har ført til at de fikk ICD.

\section{Dagens praksis}

Haukeland universitetssjukehus bruker hjemmemonitoreringssystem for alle pasientene med ICD. Hvilken type monitor avhenger av ICDprodusent, og oppfølgingen er noe ulik. To sykepleiere ved hjerteavdelingens poliklinikk jobber med å følge opp pasienter med ICD og hjemmemonitor, underviser pasientene i systemene og bruken av monitoren.

Sykepleierne jobber to dager i uken hver med å gå gjennom de planlagte innsendingene.

\section{三 «Pasientene får alltid telefon om resultatet av overføringen, både planlagte og uplanlagte sendinger.»}


Dersom monitoren foretar uplanlagte sendinger fordi det har oppstått en hendelse, vil ansvarlig lege eller sykepleier motta en e-post om dette. Så snart helsepersonellet har mulighet, ser de gjennom dataene, hovedsakelig i poliklinikkens åpningstid. Sykepleierne journalfører rapporter, som videre godkjennes av kompetent kardiolog i ICD-behandling. Pasientene får alltid telefon om resultatet av overføringen, både planlagte og uplanlagte sendinger.

Om den planlagte sendingen ikke registreres som gjennomført, blir pasientene kontaktet for å avklare årsaken til dette og sette opp ny avtale for overføring. Pasientene kan også ringe inn til en sykepleier. Selv om telefonen ikke er åpen alle dager, blir nummeret lagret og pasientene ringt opp igjen.

Hjerteavdelingen ved Haukeland universitetssjukehus tilbyr kurs for pasienter med nyimplantert ICD. Kurset er i samarbeid med Lærings- og Meistringssenteret ved sykehuset og ICD-gruppen til Landsforeningen for hjerte- og lungesyke. Kurset tar for seg aktuelle behov hos pasienter med ICD. Pasienter og pårørende får dessuten mulighet til å møte andre i samme situasjon og treffe helsepersonell på en annen arena enn i den travle sykehushverdagen. Gjennom kursprogrammet skal pasienten få mer kunnskap om sykdommen og behandlingen med oppmerksomhet på dagliglivets utfordringer, hjemmemonitorering, fysisk aktivitet og medikamentbruk i forbindelse med hjertesykdom (27).

\section{Oppsummering}

Bruk av hjemmemonitor fører til raskere diagnostikk av medisinske hendelser og tekniske problemer med ICD, reduserer behovet for sykehusinnleggelser og reduserer dødeligheten for denne pasientgruppen. Dersom ICD-pasienten har mistanke om eller opplever hjerterytmeforstyrrelse eller elektrisk sjokk fra ICDen, kan bruk av hjemmemonitor raskt avklare om det er behov for undersøkelse på poliklinikken eller legevakten, eller innleggelse i sykehus. 
Å leve med sykdommen som førte til at ICD var nødvendig, påvirker som regel pasientenes livskvalitet. Det må tilrettelegges for at pasientene skal føle den tryggheten ICD faktisk gir dem. Det er viktig at pasientene føler at de blir sett og får tilstrekkelig oppfølging, selv om de ikke møter så ofte til fremmøtekontroller av ICD-en. Slik trygghet oppnås ved at pasientene følges opp av leger og sykepleiere med god fagkunnskap innen ICD-behandling. Erfaringsmessig har denne kompetansen hos helsepersonell stor innvirkning på hvor tilfredse pasientene er med hjemmemonitoreringen. For at pasientene skal få best nytte av hjemmemonitorering av ICD, er det viktig med tidlig og god opplæring, med oppmerksomhet på egenomsorg og praktisk brukermedvirkning. Pasientene må få tydelig beskjed om at hjemmemonitorering av ICD ikke erstatter medisinske kontroller hos fastlege, hjertespesialist og på hjertesviktpoliklinikker.

\section{Referanser}

1. Platou ES, Steen T. Norsk pacemaker- og ICDstatistikk for 2016. Hjerteforum 2017;2(30):56-66.

2. Wilkoff BL, Auricchio A, Brugada J, Cowie M, Ellenbogen KA, Gillis AM et al. HRS/EHRA expert consensus on the monitoring of Cardiovascular Implantable Electronic Devices (CIEDs): Description of techniques, indications, personnel, frequency and ethical considerations. Europace 2008;10:707-25.

\section{Burri H, Senouf D. Remote monitoring and} follow-up of pacemakers and implantable cardioverter defibrillators. Europace 2009;11:701-9.

4. Færestrand S. Telekardiologi for fjernmonitorering av pacemaker og ICD. Hjerteforum2010;23(3):37-54. 
5. Sticherling C, Kühne M, Schaer B, Altmann D, Osswald S. Remote monitoring of cardiovascular implantable electronic devices: prerequisite or luxury? Swiss Med Wkly 2009;139(41-42):596-601.

6. Thylén I. Vård av patient med ICD. I: Fridlund B, Malm D, Mårtensson J (red.). Kardiologisk omvårdnad. Lund: Studentlitteratur; 2012. (s. 151-73).

7. Norekvål TM, Peersen LRL, Seivaag K, Fridlund B, Wentzel-Larsen T. Temporal trend analysis of nurses' knowledge about implantable cardioverter defibrillators. Nurs Crit Care 2015;20;(3):1463-54.

8. Priori SG, Blomström-Lundqvist C, Mazzanti A, Blom N, Borggrefe M, Camm J et al. ESC guidelines for the management of patients with ventricular arrhythmias and the prevention of sudden cardiac death. Europace 2015;17(11):1601-87.

9. Platou ES. Pacemaker og ICD-behandling. I: Forfang K, Istad H (red.). Kardiologi : Klinisk veileder. Oslo: Gyldendal Norsk Forlag; 2012. (s. 20212).

10. Sigurd B. Sandøe E. Klinisk elektrokardiologi. Bingen: Publishing Partners Verlags; 2002.

11. Braunschweig F, Boriani G, Bauer A, Hatala R, Herrmann-Lingen C, Kautzner J et al. Management of patients receiving implantable cardiac defibrillator shock. Recommendations for acute and long-term patient management. Europace 2010;12:1673-90.

12. Petersen HH, Larsen MC, Nielsen OW, Kensing F, Svendsen JH. Patient satisfaction and suggestion for improvement of remote ICD monitoring. J Interv Card Electrophysiol 2012;34:31724. 
13. Crossley GH, Boyle A, Vitense H, Chang Y, Mead H. The CONNECT (Clinical Evaluation of Remote Notification to Reduce Time to Clinical Device) trial: The value of wireless remote monitoring with automatic clinician alerts. J Am Coll Cardiol 2011;57(10):1181-89.

14. Lerdal A, Fagermoen MS (red.). Læring og mestring - et helsefremmende perspektiv i praksis og forskning. Oslo: Gyldendal Norsk Forlag; 2011.

15. Andreassen TA. Brukermedvirkning i helsetjenesten. Oslo: Gyldendal Norsk Forlag; 2005.

16. Hansen H (red.). Faglig skjønn og brukermedvirkning. Bergen: Fagbokforlaget; 2010.

17. Lov 2. juli 199 nr. 63 om pasient- og brukerrettigheter m.v (pasient- og brukerrettighetsloven). Tilgjengelig fra: https://lovdata.no/dokument/NL/lov/1999-07-02-63 (nedlastet 16.08.2017).

18. Sears SF, Matchett M, Conti JB. Effective management of ICD patient psychosocial issues and patient critical events. J Cardiovasc Electrophysiol 2009;20:1297-304.

19. Tveiten S. Den vet best hvor skoen trykker ... Om veiledning i empowermentprosessen. Bergen: Fagbokforlaget; 2007.

20. Eide H, Eide T. Kommunikasjon i praksis: relasjoner, samspill og etikk i sosialfaglig arbeid. Oslo: Gyldendal Norsk Forlag; 2007.

21. Morken IM, Norekvål TM, Bru E, Larsen AI, Karlsen B. Perception of healthcare professionals' support, shock anxiety and device acceptance among implantable cardioverter defibrillator recipients. J Adv Nurs 2014 Sept;70(9);2061-71. 
22. Varma N, Epstein AE, Irimpen A, Schweikert R, Love C. Efficacy and safety of automatic remote monitoring for implantable cardioverter- defibrillator follow-up. Circulation 2010;122:325-32.

23. Raatikainen MJP, Uusimaa P, van Ginneken MME, Janssen JPG, Linnaluoto M. Remote monitoring of implantable defibrillator patients: a safe, time-saving, and cost-effective means for follow-up. Europace 2008;10:1145-51.

24. Thomas SA, Friedmann E, Kao CW, Inguito P, Metcalf M, Kelley F et al. Quality of life and psychological status of patients with implantable cardioverter defibrillators. Am J Crit Care 2006;15:389-98.

25. Ricci RP, Morichelli L, Quatra L, Sassi A, Porfili A, Laudadio MT et al. Long-term patient acceptance of and satisfaction with implanted device remote monitoring. Europace 2010;12(5):674-9.

26. Fålun N, Instenes I, Norekvål TM. Hjertesvikt krever spesialkompetanse. Sykepleien 2013;13:68-70. Tilgjengelig fra:

https://sykepleien.no/forskning/2013/11/hjertesviktkrever-spesialkompetanse (nedlastet 23.08.2017).

27. Helse Bergen, Haukeland universitetssjukehus. ICD - $\AA$ leve med hjertestartar. Tilgjengelig fra: https://helse-bergen.no/arrangementer/icd-a-leve-medhjertestartar (nedlastet 05.09.2017). 